\title{
GREEN'S FUNCTION OF THE PROBLEM OF BOUNDED SOLUTIONS IN THE CASE OF A BLOCK TRIANGULAR COEFFICIENT
}

\author{
Vitali G. Kurbatov and Irina V. KuRbatova
}

Abstract. It is well known that the equation $x^{\prime}(t)=A x(t)+f(t), t \in \mathbb{R}$, where $A$ is a bounded linear operator, has a unique bounded solution $x$ for any bounded continuous free term $f$, provided the spectrum of the coefficient $A$ does not intersect the imaginary axis. This solution can be represented in the form

$$
x(t)=\int_{-\infty}^{\infty} \mathscr{G}(s) f(t-s) d s .
$$

The kernel $\mathscr{G}$ is called Green's function. In this paper, the case when $A$ admits a representation by a block triangular operator matrix is considered. It is shown that the blocks of $\mathscr{G}$ are sums of special convolutions of Green's functions of the diagonal blocks of $A$.

Mathematics subject classification (2010): 47A60, 47A80, 34B27, 34B40, 34D09.

Keywords and phrases: Bounded solutions problem, Green's function, divided difference with operator arguments, block matrix, causal operator.

\section{REFERENCES}

[1] R. R. AkHmerov And V. G. Kurbatov, Exponential dichotomy and stability of neutral type equations, J. Differential Equations 76 (1988), no. 1, 1-25, MR 964610.

[2] A. G. BASKAKOV, Estimates for the Green's function and parameters of exponential dichotomy of a hyperbolic operator semigroup and linear relations, Mat. Sb. 206 (2015), no. 8, 23-62, (in Russian); English translation in Sb. Math., 206 (2015), no. 8, 1049-1086, MR 3438589.

[3] R. Bellman, Introduction to matrix analysis, McGraw-Hill Book Co., New York-Toronto-London, 1960, MR 0122820.

[4] A. A. BoichuK AND A. A. PoKUtnit, Bounded solutions of linear differential equations in a Banach space, Nonlinear Oscillations 9 (2006), no. 1, 3-14, MR 2369770.

[5] N. BourbakI, Éléments de mathématique. Fascicule XXXII. Théories spectrales. Chapitre I: Algèbres normées. Chapitre II: Groupes localement compacts commutatifs, Actualités Scientifiques et Industrielles, No. 1332, Hermann, Paris, 1967, (in French), MR 0213871.

[6] F. Carbonell, J. C. Jímenez, and L. M. Pedroso, Computing multiple integrals involving matrix exponentials, J. Comput. Appl. Math. 213 (2008), no. 1, 300-305, MR 2382698.

[7] M. Ceballos, J. NúñEz, And A. F. TEnorio, Complete triangular structures and Lie algebras, Int. J. Comput. Math. 88 (2011), no. 9, 1839-1851, MR 2810866.

[8] Wai-Shun Cheung, Lie derivations of triangular algebras, Linear and Multilinear Algebra 51 (2003), no. 3, 299-310, MR 1995661.

[9] C. CHICONE AND Y. LATUSHKIN, Evolution semigroups in dynamical systems and differential equations, Mathematical Surveys and Monographs, vol. 70, American Mathematical Society, Providence, RI, 1999, MR 1707332.

[10] JU. L. DALECKIĬ AND M. G. KREǏN, Stability of solutions of differential equations in Banach space, Translations of Mathematical Monographs, vol. 43, American Mathematical Society, Providence, RI, 1974, MR 0352639.

[11] PH. I. Davies And N. J. Higham, A Schur-Parlett algorithm for computing matrix functions, SIAM J. Matrix Anal. Appl. 25 (2003), no. 2, 464-485 (electronic), MR 2047429.

[12] CH. DAVIS, Explicit functional calculus, Linear Algebra and Appl. 6 (1973), 193-199, MR 0327792. 
[13] C. A. Desoer And M. VidyASAGAR, Feedback systems: input-output properties, Academic Press, New York-London, 1975, MR 0490289.

[14] L. Dieci AND A. PAPINI, Padé approximation for the exponential of a block triangular matrix, Linear Algebra Appl. 308 (2000), no. 1-3, 183-202, MR 1751139.

[15] M. A. Evgrafov, Analiticheskie funktsii [Analytic functions], Izdat. "Nauka", Moscow, 1965, (in Russian), MR 0188404.

[16] A. Feintuch And R. SAeKs, System theory: A Hilbert space approach, Pure and Applied Mathematics, vol. 102, Academic Press, Inc. [Harcourt Brace Jovanovich, Publishers], New York-London, 1982, MR 663906.

[17] R. P. FEYNMAN, An operator calculus having applications in quantum electrodynamics, Physical Rev. (2) 84 (1951), 108-128, MR 0044379

[18] A. O. GEL'FOND, Calculus of finite differences, International Monographs on Advanced Mathematics and Physics, Hindustan Publishing Corp., Delhi, 1971, Translation of the third Russian edition, MR 0342890 .

[19] H. Ghahramani, Zero product determined triangular algebras, Linear and Multilinear Algebra 61 (2013), no. 6, 741-757, MR 3005653.

[20] M. I. GIL', Operator functions and localization of spectra, Lecture Notes in Mathematics, vol. 1830, Springer-Verlag, Berlin, 2003, MR 2032257.

[21] S. K. Godunov, Ordinary differential equations with constant coefficient, Translations of Mathematical Monographs, vol. 169, American Mathematical Society, Providence, RI, 1997, Translated from the 1994 Russian original by Tamara Rozhkovskaya, MR 1465434.

[22] S. K. Godunov, Lectures on modern aspects of linear algebra, University series, vol. 12, Science book, Novosibirsk, Russia, 2002, (in Russian).

[23] I. Gohberg, S. Goldberg, And M. A. KAAshoek, Classes of linear operators. Vol. II, Operator Theory: Advances and Applications, vol. 63, Birkhäuser Verlag, Basel, 1993, MR 1246332.

[24] I. Gohberg AND M. G. KREǏN, Theory and applications of Volterra operators in Hilbert space, Translations of Mathematical Monographs, vol. 24, American Mathematical Society, Providence, RI, 1970, MR 0264447.

[25] D. L. GoOdWIN AND I. KUPROV, Auxiliary matrix formalism for interaction representation transformations, optimal control, and spin relaxation theories, The Journal of Chemical Physics 143 (2015), 084113-1-084113-7.

[26] Jin Kyu Han, Hong Youl Lee, And Woo Young Lee, Invertible completions of $2 \times 2$ upper triangular operator matrices, Proc. Amer. Math. Soc. 128 (2000), no. 1, 119-123, MR 1618686.

[27] Ph. Hartman, Ordinary differential equations, second ed., Classics in Applied Mathematics, Society for Industrial and Applied Mathematics (SIAM), Philadelphia, PA, 2002, MR 1929104.

[28] D. HEnRY, Geometric theory of semilinear parabolic equations, Lecture Notes in Mathematics, vol. 840, Springer-Verlag, Berlin-New York, 1981, MR 610244.

[29] N. J. Higham, A survey of condition number estimation for triangular matrices, SIAM Rev. 29 (1987), no. 4, 575-596, MR 917696.

[30] E. Hille AND R. S. Phillips, Functional analysis and semi-groups, American Mathematical Society Colloquium Publications, vol. 31, Amer. Math. Soc., Providence, Rhode Island, 1957, MR 0089373.

[31] CH. Jordan, Calculus of finite differences, third ed., Chelsea Publishing Co., New York, 1965, MR 0183987.

[32] R. V. KADISON AND I. M. SINGER, Triangular operator algebras. Fundamentals and hyperreducible theory, Amer. J. Math. 82 (1960), 227-259, MR 0121675.

[33] C. S. KENNEY AND A. J. LAUB, A Schur-Fréchet algorithm for computing the logarithm and exponential of a matrix, SIAM J. Matrix Anal. Appl. 19 (1998), no. 3, 640-663 (electronic), MR 1611163.

[34] D. KRESSNER, R. LuCE, AND F. STATTI, Incremental computation of block triangular matrix exponentials with application to option pricing, arXiv:1703.00182 (2017).

[35] V. G. KURBATOV, Linear functional-differential equations of neutral type and the retarded spectrum, Sibirskii Matematicheskii Zhurnal 16 (1975), no. 3, 538-550, (in Russian); English translation in Siberian Mathematical Journal, 16 (1975), no. 3, 412-422, MR 0402226.

[36] V. G. Kurbatov, On the stability of functional-differential equations, Differencial' nye Uravnenija 17 (1981), no. 6, 963-972, (in Russian); English translation in Differential Equations, 17 (1981), no. 6, 611-618, MR 620094. 
[37] V. G. Kurbatov, Functional differential operators and equations, Mathematics and its Applications, vol. 473, Kluwer Academic Publishers, Dordrecht, 1999, MR 1702280.

[38] V. G. Kurbatov And I. V. Kurbatova, Computation of a function of a matrix with close eigenvalues by means of the Newton interpolating polynomial, Linear and Multilinear Algebra 64 (2016), no. 2, 111-122, MR 3434507

[39] V. G. Kurbatov And I. V. Kurbatova, Computation of Green's function of the bounded solutions problem, Computational Methods in Applied Mathematics 18 (2018), no. 4, 673-685, MR 3859261.

[40] V. G. Kurbatov, I. V. Kurbatova, and M. N. Oreshina, Analytic functional calculus for two operators, arXiv:1604.07393v (2016).

[41] W. R. LePAGE, Complex variables and the Laplace transform for engineers, Dover Publications, Inc., New York, 1980, Corrected reprint of the 1961 original, MR 616824.

[42] M. LUTZKY, Parameter differentiation of exponential operators and the Baker-Campbell-Hausdorff formula, J. Mathematical Phys. 9 (1968), 1125-1128.

[43] J. L. MASSERA AND J. J. SCHÄFFER, Linear differential equations and function spaces, Pure and Applied Mathematics, Vol. 21, Academic Press, New York-London, 1966, MR 0212324.

[44] I. NAJFEld AND T. F. HaVEl, Derivatives of the matrix exponential and their computation, Adv. in Appl. Math. 16 (1995), no. 3, 321-375, MR 1342832.

[45] A. A. PAnKov, Bounded and almost periodic solutions of nonlinear operator differential equations, Mathematics and its Applications (Soviet Series), vol. 55, Kluwer Academic Publishers, Dordrecht, 1990, Translated from the 1985 Russian edition, MR 1120781.

[46] B. N. PARLETT, A recurrence among the elements of functions of triangular matrices, Linear Algebra and Appl. 14 (1976), no. 2, 117-121, MR 0448846.

[47] A. V. PechKurov, Bisectorial operator pencils and the problem of bounded solutions, Izv. Vyssh. Uchebn. Zaved. Mat. (2012), no. 3, 31-41, (in Russian); English translation in Russian Math. (Iz. VUZ), 56 (2012), no. 3, 26-35, MR 3076516.

[48] P. C. Rosenbloom, Bounds on functions of matrices, Amer. Math. Monthly 74 (1967), 920-926, MR 0222102.

[49] W. Rudin, Functional analysis, first ed., McGraw-Hill Series in Higher Mathematics, McGraw-Hill Book Co., New York-Düsseldorf-Johannesburg, 1973, MR 0365062.

[50] B. VAN DER POL AND H. BRemmer, Operational calculus. Based on the two-sided Laplace integral, third ed., Chelsea Publishing Co., New York, 1987, MR 904873.

[51] CH. F. VAN LoAn, The sensitivity of the matrix exponential, SIAM J. Numer. Anal. 14 (1977), no. 6, 971-981, MR 0468137.

[52] CH. F. VAN LOAN, Computing integrals involving the matrix exponential, IEEE Trans. Automat. Control 23 (1978), no. 3, 395-404, MR 0494865.

[53] R. M. Wilcox, Exponential operators and parameter differentiation in quantum physics, J. Mathematical Phys. 8 (1967), 962-982, MR 0234689.

[54] J. C. Willems, The analysis of feedback systems, The MIT Press, Cambridge, 1971. 